Tjalling C. Koopmans Research Institute

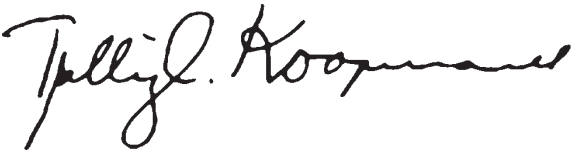

Discussion Paper Series nr: 11-13

\title{
FOMC Communication Policy and the Accuracy of Fed Funds Futures
}

Menno Middeldorp 


\title{
Tjalling C. Koopmans Research Institute Utrecht School of Economics \\ Utrecht University
}

Janskerkhof 12

3512 BL Utrecht

The Netherlands

telephone $\quad+31302539800$

fax +31302537373

website www.koopmansinstitute.uu.nl

The Tjalling C. Koopmans Institute is the research institute and research school of Utrecht School of Economics.

It was founded in 2003, and named after Professor Tjalling C. Koopmans, Dutch-born Nobel Prize laureate in economics of 1975.

In the discussion papers series the Koopmans Institute publishes results of ongoing research for early dissemination of research results, and to enhance discussion with colleagues.

Please send any comments and suggestions on the Koopmans institute, or this series to J.M.vanDort@uu.nl

ontwerp voorblad: WRIK Utrecht

\author{
How to reach the authors \\ Please direct all correspondence to the first author. \\ Menno Middeldorp \\ Federal Reserve Bank of New York \\ 33 Liberty Street \\ New York, NY 10045 \\ U.S.A. \\ Utrecht University \\ Utrecht School of Economics \\ Janskerkhof 12 \\ 3512 BL Utrecht \\ The Netherlands. \\ E-mail: Menno.Middeldorp@ny.frb.org
}




\title{
FOMC Communication Policy and the Accuracy of Fed Funds Futures
}

\author{
Menno Middeldorp \\ Federal Reserve Bank NY
}

U.S.A.

Utrecht School of Economics

Utrecht University

July 2011

Federal Reserve Bank of New York Staff Reports, no. 491

\begin{abstract}
Over the last two decades, the Federal Open Market Committee (FOMC), the rate-setting body of the United States Federal Reserve System, has become increasingly communicative and transparent. According to policymakers, one of the goals of this shift has been to improve monetary policy predictability. Previous academic research has found that the FOMC has indeed become more predictable. Here, I contribute to the literature in two ways. First, instead of simply looking at predictability before and after the Fed's communication reforms in the 1990s, I identify three distinct periods of reform and measure their separate contributions. Second, I correct the interest rate forecasts embedded in fed funds futures contracts for risk premiums, in order to obtain a less biased measure of predictability. My results suggest that the communication reforms of the early 1990s and the "guidance" provided from 2003 significantly improved predictability, while the release of the FOMC's policy bias in 1999 had no measurable impact. Finally, I find that FOMC speeches and testimonies significantly lower short-term forecasting errors.
\end{abstract}

Keywords: central bank communication, central bank transparency, futures pricing, financial market efficiency

JEL classification: D83, E58, G13, G14

\section{Acknowledgements}

The author thanks Allard Bruinshoofd, Deborah Perelmuter, Jan Potters, Martijn Prook, Matthew Raskin, Stephanie Rosenkranz, and seminar participants at the Federal Reserve Bank of New York. Special thanks to Clemens Kool for extensive comments on several drafts. The author also gratefully acknowledges the support of the Rabobank Economic Research Department and the Hong Kong Institute for Monetary Research, where parts of the research presented here were conducted in the context of his doctoral dissertation for Utrecht University. The views expressed in this paper are those of the author and do not necessarily reflect the position of the Federal Reserve Bank of New York or the Federal Reserve System.

This paper presents preliminary findings and is being distributed to economists and other interested readers solely to stimulate discussion and elicit comments. The views expressed in this paper are those of the author and are not necessarily reflective of views at the Federal Reserve Bank of New York or the Federal Reserve System. Any errors or omissions are the responsibility of the author. 


\section{Introduction}

Central banks worldwide have shifted to more active and transparent communication policies over the past quarter century. There are several reasons for this change, including non-economic ones like the need for independent central banks in democratic societies to explain their actions. Another reason is the impact of communication on the functioning of financial markets. Bernanke (2004) asserts that "clear communication helps to increase the near-term predictability of FOMC rate decisions, which reduces risk and volatility in financial markets and allows for smoother adjustment of the economy to rate changes."

As the literature review in the following section illustrates, academic research widely supports the idea that transparency improves predictability. The general approach that has been taken is to identify an important reform in communication policy and compare average predictability before and after. This makes the most sense for countries that have concentrated their reforms, like those that switched to an inflation targeting framework and its accompanying communication tools. The FOMC's reforms, however, were conducted gradually over more than fifteen years. As a result it is possible to identify the impact of particular reforms - or at least series of reforms - separately. No earlier research that I am aware of has pursued such an approach, motivating the work documented below. Specifically, I look at the effects of three periods of reform: first, the early 1990's, starting with the new FOMC minutes; second, reforms around the turn of the millennium when the FOMC started to reveal its policy bias directly after meetings; third, after 2003, when the FOMC started to offer explicit guidance about the direction of policy rates. More information on these reforms can be found in Section 3.

To evaluate the impact of transparency reforms on predictability one needs a measure of the latter. Two methods are commonly used in the literature. The first is to interpret the reaction of market interest rates after policy announcements as an indicator of how accurate markets had been in anticipating new policy. The second is to extract expectations from the financial markets, either from the yield curve or interest rate futures. The main advantage of the latter approach is that expectations are available over longer horizons than just between policy meetings. The main disadvantage is that market expectations may be biased by risk premiums. Piazzesi and Swanson (2008) show how to use business cycle indicators to correct for risk premiums in the Fed funds future rate. I describe my application of their technique in Section 4. To the best of my knowledge, I am the first to adopt their approach to study monetary policy predictability.

My results, discussed in section 5, suggest that the introduction of FOMC "guidance" in 2003 resulted in the greatest improvement in predictability, with significant declines in forecast errors out to three months. The immediate release of the FOMC's "policy bias" in 1999, which was later adjusted and relabeled 
the "balance-of-risks assessment", failed to have a significant effect on errors. Finally, the reforms of the early 1990s also lowered forecast errors significantly, up to five months ahead.

Speeches by members of the Federal Reserve Board and Congressional testimony by FOMC members are also important channels of communication. Adding the number of speeches and testimonies per month to the analysis shows a significant additional improvement to the predictability of policy. Section 6 provides robustness checks for the presented results.

\section{Review of literature on predictability}

A significant portion of the transparency literature ${ }^{1}$ studies the relationship between communication and the predictability of monetary policy in the financial markets. ${ }^{2}$ Some theoretical papers have counter-intuitively suggested that more transparency may actually impair predictability. A significant body of empirical research, however, tends to find the opposite effect. There are nonetheless still some ways that the empirical literature can be advanced, motivating the approach I take in the subsequent sections.

Intuitively, one would expect better public information to improve market functioning, in the sense that financial markets become better at predicting the outcome of unrealized fundamentals. This is true in a basic rational expectations asset market model with exogenous public and private information. ${ }^{3}$ Under different assumptions or models, however, better public information can hamper market functioning.

Probably the best known example is Morris and Shin (2002). They present a model where the profits of individual agents depend not only on fundamental values but also on the expectations of others (clearly an issue in any market where assets can be sold before the realization of their fundamental value). Under these circumstances a sufficiently clear signal from the central bank can act as a coordinating point that could distract market participants from their private information and possibly away from fundamentals. Svensson (2006) argues that this conclusion is only valid for the unlikely situation that public signals

\footnotetext{
${ }^{1}$ Blinder, Ehrmann, Fratzscher, de Haan and Jansen (2008) and Cruijssen and Eijffinger (2007) offer overviews of the broader literature on transparency and monetary policy.

${ }^{2} \mathrm{~A}$ related strand of the literature does not address predictability in the financial markets but examines the usefulness of central bank communication in contructing forecasts of monetary policy. Some studies have simply asked if communications contain predictive power in itself; examples include Mizen (2009) and Jansen and de Haan (2009). Other studies examine if communication is useful in improving models that forecast monetary policy, such as the Taylor rule; recent examples are Sturm and de Haan (2009) for the ECB and Hayo and Neuenkirch (2009) for the Fed.

${ }^{3}$ See Kool, Middeldorp and Rosenkranz (2011), where the case of exogenous private information is equivalent to holding the fraction of informed traders constant.
} 
are less precise than private information. However, Demertzis and Hoeberichts (2007) add costly information acquisition to Morris and Shin (2002)'s model and find that it strengthens the result.

Another theoretical model by Dale, Orphanides and Osterholm (2008) demonstrates that if the private sector is not able to learn the precision of the central bank's information, it may overreact to central bank communication. Kool et al. (2011) find that public information can crowd out investment in private information, which hampers predictability, a conclusion supported by the experimental work of Middeldorp and Rosenkranz (2011).

Despite the theoretical caveats, the vast majority of empirical research on transparency has concluded that in practice transparency improves the predictability of monetary policy in the financial markets. The general approach is to select a watershed communication reform and test the difference between predictability before and afterwards. US studies typically use the first announcement of the Federal Open Market Committee's (FOMC) rate decisions in February 1994, while for other countries the introduction of an inflation target, with its accompanying communication tools, is used. One can measure predictability in at least two ways. The first is to ascertain how surprised financial markets are by policy decisions. The second extracts expectations from the yield curve or futures to see how accurate they are.

The first approach to assessing the predictability of monetary policy involves examining market movements close to policy decisions. Little reaction in money market rates following a policy rate change suggests that it has been priced in and that policy is predictable. Money market movements prior to the decision in the same direction as the rate change can be interpreted as anticipating the move. Swanson (2006) finds that US interest rates show less reaction to Fed decisions over the period where the Fed reformed its communication policy. Ehrmann and Fratzscher (2007b) conclude that FOMC communication reforms of 1999 did not reduce surprises (although they present evidence that they did result in financial markets focusing more on the post-meeting statement rather than other forms of Fed communication).

Holmsen, Qvigstad, Øistein Røisland and Solberg-Johansen (2008) find lower volatility on the days the Norges Bank announced its decisions after it started to release forecasts of its own interest rates. Murdzhev and Tomljanovich (2006) and Coppel and Connolly (2003) show that policy changes are better anticipated in, respectively, six and eight advanced economies. Although such an approach is fairly intuitive and clear cut, its disadvantage is that it only provides a measure of market expectations between meetings and at the time of rate announcements. Communication reforms that allow market interest rates to anticipate monetary policy earlier than one meeting ahead can't be identified.

A second method is to measure market expectations of monetary policy and examine how accurate these are. Typically expectations are either ex- 
tracted from the yield curve or futures data. Here too, findings suggest that transparency improves predictability. Rafferty and Tomljanovich (2002) and Lange, Sack and Whitesell (2003) find better accuracy for the US Treasury yield curve. Lildholdt and Wetherilt (2004) use a term structure model to show an improvement in the predictability of UK monetary policy. Similarly, Tomljanovich (2004) extracts expectations from bond yield curves and finds that forecast errors decline in seven advanced economies after transparency reforms.

Regarding futures rates, Swanson (2006) and Carlson, Craig, Higgins and Melick (2006) find that the Fed funds futures are better able to predict US monetary policy after communication reforms. Kwan (2007) concludes that forward looking language or guidance, introduced in 2003, has helped to lower the average error between the Fed funds futures and the actual outcome of the Fed funds rate.

The disadvantage of using bond market expectations, is that such estimates are likely to be biased. The failure of the expectations hypothesis for the Treasury yield curve is a well-documented empirical result (e.g. Cochrane and Piazzesi (2005), Campbell and Shiller (1991), Stambaugh (1988), Fama and Bliss (1987)). Risk premiums on interest rates are positive on average and timevarying. Sack (2004) and Piazzesi and Swanson (2008) show that Fed funds futures rates also include risk premiums, particularly at longer maturities. Piazzesi and Swanson (2008) demonstrate how to adjust Fed funds futures rates for time-varying risk premiums using business cycle data. I apply their method in the analysis below. A more detailed description of their approach is provided in Section 4.

\section{Identifying FOMC communication reforms with overlapping dummies}

To analyze the relationship between transparency and predictability one needs indicators for both. As I show in this section, one way the former can be attained is by the use of dummies that identify periods of different communication policies in a regression analysis. In the next section I describe an approach for measuring predictability.

Starting in the early 1990s the FOMC reformed its communication policy in a sequence of initiatives. It was a gradualist approach, which Cleveland Fed President Pianalto (2005) describes as the way that the FOMC "learned to talk." It has the advantage for researchers that it allows these reforms to be separated in time, which makes it possible to examine their impact individually. One way to do so is to use a dummy for each reform which is activated (i.e. set to 1) for the period after which each reform was implemented. These overlapping dummies 
can then be used as independent variables in a regression with a measure of predictability as the dependent variable.

Table 1 lists eight reforms that might be represented by overlapping dummy variables. Unfortunately, only a few months of data separate some of the potential dummies, making it difficult to confidently identify separate impacts on the predictability of policy. Furthermore, the more dummies one uses the greater the risk that the regression estimator will fit them to unrelated fluctuations in the data. To put in another way, one can perfectly describe any data set with sufficient dummies.

\begin{tabular}{|c|c|c|}
\hline Date & Label & Nature of Change \\
\hline 1993 Mar & Minutes & $\begin{array}{l}\text { Merging of FOMC "Minutes of Actions" and "Policy Record" into } \\
\text { one new document labeled the "Minutes of the FOMC" }\end{array}$ \\
\hline $1994 \mathrm{Feb}$ & Statement & First post-meeting statement with qualitative description of change in policy \\
\hline 1994 Aug & Rationale & Some reasoning behind the decision is added to the statement \\
\hline $1995 \mathrm{Jul}$ & Fed funds target & Inclusion of actual numerical Fed funds target in statement \\
\hline 1999 May & Bias & Inclusion of FOMC's asymmetric policy directive in statement \\
\hline $2000 \mathrm{Jan}$ & Balance of risks & $\begin{array}{l}\text { Revised statement language discussing balance of risks towards growth or } \\
\text { inflation rather than bias for Fed funds target }\end{array}$ \\
\hline 2002 Mar & FOMC vote & Inclusion of vote with name(s) of dissenters in statement \\
\hline 2003 Aug & Guidance & $\begin{array}{l}\text { Statement language explicitly indicating the likely direction of rates } \\
\text { over extended period }\end{array}$ \\
\hline 2005 Jan & Earlier minutes & Minutes released three weeks after meeting \\
\hline 2007 Nov & $\begin{array}{l}\text { Enhanced } \\
\text { projections }\end{array}$ & More detailed, frequent and extended projections \\
\hline
\end{tabular}

Table 1: List of FOMC communication reforms 1993-2007

To avoid overfitting the sample I choose three reforms (boldface in Table 1) that are separated by over four years and that are followed by at least one interest rate cycle. These are: first, the release of the FOMC minutes; second, the release of the FOMC's policy bias in the statement; and third the "guidance" or explicit language in the statement about the likely direction of interest rates. I argue in the remainder of this section that these are the most natural points to turn the overlapping dummies on (i.e. set the values to 1) and that, particularly for the first dummy and to some degree for the second, they are markers for a series of related reforms that are too close to separate statistically. Later on, in Section 5 I present the regression results using these dummies. Section 6 compares these results to those of alternative specifications that use different starting points for the dummies and shows that the conclusions of the analysis are not sensitive to variations in the starting points. 


\subsection{Dummy 1: new minutes and the FOMC statement}

The traditional choice for the starting point of the FOMC's move towards greater transparency is the February 1994 introduction of the post-meeting FOMC statement, in which the public was immediately informed of changes in Fed policy. The actual impact of the statement, however, was not really that momentous. The announcement itself, in the words of former Fed officer Stephen Axilrod (2009), who for many years was the daily link between the Chairman and the open markets desk, "had the advantage of eliminating the remote possibility that actions by the FOMC's manager for open market operations could inadvertently mislead the market about the Committee's decision". Generally the markets quickly figured out that the FOMC had changed the interest rate target, even though the FOMC had not told them. It thus seems unlikely to have made much difference in the outlook for a month or more ahead, which are the horizons of predictability that I measure below.

Although announcing the change in the Fed funds rate target may not have been particularly substantive, for many researchers it does make sense as a starting point for a general trend towards transparency. The statement became more informative as it evolved and became one of (if not the) most widely reported and quoted FOMC communication tool. Starting in August 1994 the FOMC included its reasoning behind the Fed rate decision in the statement, although this was still more concise and less descriptive than the reasoning provided in statements in later years. It did not contain a quantitative Fed funds target until 1995 and before 1999 it was only released if the FOMC actually changed policy (the last change coincides with the release of the asymmetric policy directive, discussed below). It is thus reasonable to see the February 1994 announcement as preceding a series of reforms that together were indeed substantive.

However, if one is interested in identifying the starting point of this reform period, the March 1993 introduction of the FOMC minutes is a more logical choice because it actually was the very first reform of the period. Granted, it looks at least as innocuous as the release of the statement. The new minutes were the product of merging two earlier FOMC documents called the "Minutes of Actions" and the "Policy Record" that were released after the subsequent FOMC meeting. Although the minutes later evolved into a somewhat more descriptive document, it essentially contained the same information as the earlier reports and was initially released with the same delay. The creation of the new minutes, however, was not motivated by administrative efficiency but by a more substantive desire to achieve better communication. According to the transcripts of the first meeting of which the new minutes were released, there was a feeling within the FOMC that "the public, including important public policy officials, has very little appreciation for the quantity and detail of material that we already release" and so the idea was to make the new minutes

more "convenient and easily accessible." Consequently there is a case to be 
made that, even though the substance was not markedly different, it raised the awareness and accessibility of the information available, just as the FOMC had intended. Indeed, Tomljanovich (2004) finds evidence that the improvement in the predictability of monetary policy occurs a year earlier than an hypothesized break-point of February 1994, thus lending further support to the using the release of the new minutes as the starting point for the first dummy.

\subsection{Dummy 2: Bias and outlook}

May 1999 saw the FOMC announcing its "tilt" or "bias" for future policy in its post-meeting statement. It was an important shift because the FOMC started to systematically say something about the balance of risks that could steer future policy in a particular direction. The possibility of an asymmetric policy directive had existed since 1983. Technically it allowed a change in monetary policy between meetings in the direction of the "bias" without the consent of the full FOMC. Since the policy directive is contained in the minutes, essentially the decision to announce it directly after the meeting brought it to the public around six weeks earlier. Many financial markets participants, however, saw it as a deliberate signal of the intentions of the FOMC. According to St. Louis Fed President Poole (2003), "many members of the FOMC believed the market overreacted to the May tilt statement and to subsequent tilt statements as well" which motivated a change in language in January 2000 to a "balance-of-risks" to price stability and growth. Poole (2003) says that it was "the FOMC's stated intention that its new "balance-of-risks" was not to be interpreted as an indicator of future FOMC actions." Rasche and Thornton (2002) present evidence that, nevertheless, analysts still used it to form such expectations.

\subsection{Dummy 3: Interest rate guidance}

Starting in August 2003 the FOMC began sending explicit signals about the likely stance of policy in the future. Both the overt nature of the signal and its longer horizon were important changes. In 2003 the statement included the text "policy accommodation can be maintained for a considerable period." In 2004, when the FOMC started hiking rates, it said ". . . policy accommodation can be removed at a pace that is likely to be measured." Some reference to the potential need for further policy tightening was part of every statement before March 2007 when it was removed, according to the FOMC minutes, "in light of the increased uncertainty about the outlook for both growth and inflation." The FOMC returned to signaling the future stance of policy in December 2008 when it started to include the following in the statement, "the Committee anticipates

that weak economic conditions are likely to warrant exceptionally low levels of the federal funds rate for some time," the last part of which was adjusted in March 2009 to "an extended period." 
Even though the FOMC refrained from providing guidance during part of the period, I activate the dummy from August 2003 until the end of the sample. By doing so I am essentially saying that there is a policy in place to provide guidance whenever the FOMC is confident enough to provide a forecast. A lack of guidance is thus a message that the FOMC considers the monetary policy outlook to be uncertain. That being the case, it is best not to switch the dummy on only when guidance is provided because it would mean creating a connection between its value and confidence in the economic outlook and the better predictability that is likely to follow (at least if such confidence has some basis in subsequent reality).

\subsection{Excluding other reforms}

Above I associate three periods of reform with dummies. The first is for the early reforms which saw the FOMC providing basic information about the current target rate and the reasoning behind policy changes. The second covers implicit information about the likely direction of interest rates provided in the bias and balance-of-risks components of the statement. The third covers explicit guidance about the likely direction of interest rates.

There were, however, three other reforms that were not clearly related to the categorization of the dummies, namely the addition of the FOMC vote to the statement (March 2002), the earlier release of the minutes (January 2005) and the enhanced projections (November 2007). I do not assign them separate dummies for three reasons. First, as explained above, in order not to over fit the sample I want to use only a few dummies where each straddles at least one monetary policy cycle. Second, the FOMC vote and the earlier release of the minutes largely overlap with the "guidance" dummy, making it difficult to identify a separate effect. Third, the introduction of the enhanced projections is too close to the end of the sample (only 14 observations) to identify its impact.

In the current setup, any effect from the FOMC vote and statement will largely (in the case of the vote) or entirely (in the case of the earlier minutes) be attributed to the "guidance" dummy. However, any such effects are likely to be small and isolated. Including the vote in the statement probably gave the markets a better sense of the uncertainty surrounding the economic outlook and future rate decisions; rather than provide a clear signal about the future it is an indicator of the (lack of) precision of the FOMC's guidance. Furthermore, the vote was already included in the minutes. Adding it to the statement released the information approximately six weeks earlier. Similarly, moving the minutes forward from about six weeks to three weeks after the FOMC meeting changed the timing but probably not the nature of the release. 


\section{Fed funds futures and risk premiums}

The approach to measuring predictability used here is to compare the expectations reflected in Fed funds futures to the actual outcome of monetary policy. As explained directly below, the Fed funds are the best indicator of market expectations, but still need to be adjusted for risk premiums.

Fed funds futures contracts have been traded at the Chicago Board of Trade since October 1988. They are contracts on the average effective Fed funds rate in one of the upcoming twenty-four months. Their prices are determined by market supply and demand. When the contracts expire they are cash settled at 100 minus the average daily overnight Fed funds rate for the delivery month. For example if the average Fed funds rate equaled $4.75 \%$ in June, then on the first business day of July the June contract would be settled at 95.25. If an investor, expecting the FOMC to cut interest rates, had bought the June contract several months ago at 94 (implying an expected average funds rate of $6 \%$ ) and held it until expiration, that person would have made a positive return on investment of $1.3 \% \cdot{ }^{4}$

I use Fed funds futures prices, measured at the last day of the month, as provided by EcoWin, for contracts that expire in the upcoming one to six months. The data is complete for the entire period except for the five and six month futures, which have some missing data in 1988-1990.

The Fed funds futures have three advantages as indicators of financial market expectations of monetary policy. First, it is not necessary to derive expectations from an interest rate curve: 100 minus the current price is a straightforward forecast of the future rate. Second, the future rate relates directly to the Fed funds rate, avoiding the need to infer the Fed funds rate indirectly from expectations of another interest rate. Third, Fed funds futures contracts are the most accurate financial market predictor of the Fed funds rate. Gurkaynak, Sack and Swanson (2007) find that the federal funds futures dominate all the other securities in forecasting monetary policy on horizons out to six months.

On the other hand, Sack (2004) and Piazzesi and Swanson (2008) have established that even though the Fed funds futures are the best market forecasts of the Fed funds rate they are biased by the presence of risk premiums. In that respect there is no difference between expectations derived from the yield curve and those derived from the futures market. Piazzesi and Swanson (2008) show how to correct for risk premiums in monthly data. They demonstrate that excess returns of the futures rate above actual interest rates fluctuate in line with several business cycle indicators. Their best results are achieved by the straightforward method of regressing the excess returns on the level of the Fed funds future rate and the year-on-year changes in nonfarm payrolls measure

${ }^{4}=(95.25-94) / 94$. The face value of the contract is $\$ 5$ million, so the profit would be $\$ 62.5$ thousand per contract. 
of employment. The level of the futures forecast, $f_{t}^{n}$, is also included in the regression to control for the fact that higher excess returns accompany higher levels of interest rates.

The excess return is defined as

(1) $e_{t+n}=f_{t}^{n}-r_{t+n}$

$t \quad$ month index

$n \quad$ contract index (months $t+1$ to $t+6$ )

$e_{t+n} \quad$ excess return at $t+n$

$f_{t}^{n} \quad$ Closing rate of Fed funds future contract on last trading day of month $t$ for settlement at $t+n$

$r_{t+n} \quad$ Average Fed funds rate for month $t+n$

The benchmark regression run by Piazzesi and Swanson (2008) is

$$
\begin{array}{ll}
\text { (2) } e_{t+n}=c+\stackrel{+}{\alpha} f_{t}^{n}+\bar{\beta} p_{t-1} \\
\alpha, \beta & \text { Coefficients } \\
p_{t-1} & \text { Log payrolls } t-1 \text { minus } t-13 \text { (year-on-year employment change) } \\
c & \text { Constant }
\end{array}
$$

It is important that the regression only contains information known at the time that the future price is determined because the idea it to identify predictable excess returns. Intuitively, if the excess return is to be seen as a risk premium, then risk perception of market participants is influenced only by information available on the last trading day of month $t$. This means that the most recent payrolls data is from month $t-1$ (released on the first Friday of month $t) .{ }^{5}$ It is also necessary to use the payrolls data actually available at that time and not the revised data. ${ }^{6}$

Piazzesi and Swanson show that the coefficients in the above regression are significant for one to six month maturities, with the exception of the payrolls coefficient for the one month maturity. Below I use the Piazzesi and Swanson's approach to control for predictable and time-varying excess returns.

The measure of predictability itself is simply the forecast error of the Fed funds futures, which I define as the absolute value of the futures rate minus the corresponding actual Fed funds rate. Equation (3) is nothing more than the absolute value of Equation (1).

(3) $\left|e_{t+n}\right|=\left|f_{t}^{n}-r_{t+n}\right|$

\footnotetext{
${ }^{5}$ Using the latest release of the weekly initial jobless claims, which is closer to the last day of the month, does not improve on the results of Piazzesi and Swanson (2008).

${ }^{6}$ Vintage real-time data is available from the Philadelphia Federal Reserve Real-Time Data Research Center. Not only does one need the original unrevised t-1 value but also the revised, but not final revision, value of $\mathrm{t}-13$ that is known at $\mathrm{t}-1$.
} 


\section{$5 \quad$ Regression and results}

Equation (4) represents the exact regression specification used in the analysis below. It has two parts, the control for risk premiums described in the previous section and the dummies described in Section 3. The regression is run using monthly data from October 1988 to October 2008 (241 months).

(4) $\ln \left|e_{t+n}\right|=\chi+\gamma\left(e_{t+n}^{+} c-e_{t+n}^{-} c\right)+\alpha\left(e_{t+n}^{+} f_{t+n}^{n}-e_{t+n}^{-} f_{t+n}^{n}\right)+\beta\left(e_{t+n}^{+} p_{t}^{n}-\right.$ $\left.e_{t+n}^{-} p_{t}^{n}\right)+\delta_{1993} d_{1993}+\delta_{1999} d_{1999}+\delta_{2003} d_{2003}$

$\chi \quad$ Constant

$e_{t+n}^{+} \quad$ binary variable equal to 1 if $e_{t+n}>0$ and 0 otherwise

$e_{t+n}^{-} \quad$ binary variable equal to 1 if $e_{t+n}<0$ and 0 otherwise

$\delta \quad$ coefficients for dummies

$d_{1993}$ Binary variable, 1 for March 1993 to October 2008 (177/241 months)

$d_{1999}$ Binary variable, 1 for May 1999 to October 2008 (114/241 months)

$d_{2003}$ Binary variable, 1 for August 2003 to October 2008 (63/241 months)

Regarding the control for risk premiums, there is a small complication in that the risk premiums in Piazzesi and Swanson's equation are estimated over the excess returns. The regression above, on the other hand, is estimated on the absolute errors. The solution is to split the Piazzesi and Swanson component of the regression into two parts using the binary variables $e_{t+n}^{+}$and $e_{t+n}^{+}$, for positive errors and negative errors respectively, and then flip the sign for the latter (i.e. multiply by -1). Doing so does not affect the results of Piazzesi and Swanson correction, which can easily be confirmed by running this part of the regression both normally and with the adjustment and then comparing the identical results.

Using the natural log of the absolute forecast error as the dependent variable significantly improves the statistical properties of the model. It transforms the distribution of the absolute errors from one that is all positive and skewed, to one that is roughly symmetrical. This results in better behaved residuals and avoids the equation predicting negative absolute errors.

The above regression equation produces the results presented in Table 2. Reported are Newey-West heteroskedasticity and autocorrelation robust standard errors. 


\begin{tabular}{lcccccc}
\hline & $\mathbf{n = 1}$ & $\mathbf{n = 2}$ & $\mathbf{n = 3}$ & $\mathbf{n = 4}$ & $\mathbf{n = 5}$ & $\mathbf{n}=\mathbf{6}$ \\
\hline Constant $(\boldsymbol{\chi})$ & $-2.67 * * *$ & $-2.09 * * *$ & $-1.88 * * *$ & $-1.51 * * *$ & $-1.29 * * *$ & $-1.79 * * *$ \\
Constant $(\boldsymbol{\gamma})$ & 0.02 & $0.36 *$ & 0.31 & -0.04 & -0.15 & $-0.56 * *$ \\
Future rate $(\boldsymbol{\alpha})$ & $0.07 *$ & $0.08 *$ & $0.11 *$ & $0.13 * *$ & $0.18 * *$ & $0.35 * * *$ \\
Payrolls $(\boldsymbol{\beta})$ & $-17.02 * *$ & $-28.86 * * *$ & $-30.92 * * *$ & $-23.26 * *$ & $-30.54 * *$ & $-49.25 * * *$ \\
Minutes $(\boldsymbol{\delta 1 9 9 3 )}$ & $-0.54 * *$ & $-0.68 * * *$ & $-0.51 *$ & $-0.51 *$ & $-0.54 *$ & 0.09 \\
Bias $(\boldsymbol{\delta 1 9 9 9 )}$ & -0.28 & -0.02 & 0.00 & -0.08 & 0.04 & 0.17 \\
Guidance $(\boldsymbol{\delta 2 0 0 3})$ & $-0.95 * * *$ & $-0.79 * *$ & $-0.53 *$ & -0.16 & -0.14 & -0.14 \\
\hline
\end{tabular}

$* \mathrm{p}<10 \% * * \mathrm{p}<5 \% * * * \mathrm{p}<1 \%$

Table 2: Impact of reforms on Fed funds future errors

Results show that the communication changes following the introduction of the minutes and the guidance policy both lowered errors with varying degrees of significance. The bias, however, does not seem to have any significant effect.

The guidance policy significantly lowers errors up to three months ahead and the effects are the most substantial measured. With the exception of the eve of the subprime crisis in 2007, whenever the FOMC provided guidance it was also correct in its assessment of the future course of interest rates. As a result policy generally lowered errors. It also confirms the earlier finding by Kwan (2007) that guidance improved predictability.

The bias (May 1999) and subsequent balance-of-risks (January 2000), on the other hand, do not seem to have significantly helped markets in actually predicting monetary policy. Part of the reason may be that, as many FOMC members thought, the markets did overreact to the bias or that, as the FOMC said, the balance-of-risks statement was not a signal about future rates. Also, perhaps one should not expect too much from the release of the bias because the policy directive was already contained in the minutes, which were released about six weeks later anyway. This could explain why the biggest impact in the results happens for the one month ahead forecast, although it is still not strong enough to be significant.

The new FOMC minutes - at least as a marker for the early series of reforms - has a significant impact over the longest horizon, up to five months ahead. It is only weakly significant beyond a two month horizon. In some sense the significant long horizon effect is a surprise because the early reforms involved little signaling of future interest rates. On the other hand the more accessible minutes and the increasingly descriptive statements probably helped the market participants to better understand what motivated Fed policy and thus made them more accurate in translating their own economic expectations into policy predictions. As Bank of England Governor Mervyn King (2000) argued (just before he famously said that a "successful central bank should be boring") a better understanding of the "monetary policy reaction function" should in 
itself lead to "policy being predictable" and as such "the news should be in developments of the economy."

It may also be the case that the release of the minutes and the evolution of the statement coincided with more open Fed communication policy through all its channels, new and old. Speeches and Congressional testimony made by the Chairman and other FOMC members are channels that predate the communication reforms. To test if this channel is also important I supplement the above regression with the number of speeches per month given by Fed board members and FOMC Congressional testimony. Unfortunately, speeches are only available on the Fed Board of Governors website since June 1996, limiting my sample and necessitating the removal of the first dummy.

(5) $\ln \left|e_{t+n}\right|=\chi+\gamma\left(e_{t+n}^{+} c-e_{t+n}^{-} c\right)+\alpha\left(e_{t+n}^{+} f_{t+n}^{n}-e_{t+n}^{-} f_{t+n}^{n}\right)+\beta\left(e_{t+n}^{+} p_{t-1}^{n}-\right.$ $\left.e_{t+n}^{-} p_{t-1}^{n}\right)+\delta_{1999} d_{1999}+\delta_{2003} d_{2003}+\varsigma s$

$s \quad$ Number of Fed Board speeches and FOMC Congressional testimony

\begin{tabular}{|c|c|c|c|c|c|c|}
\hline & $n=1$ & $n=2$ & $n=3$ & $n=4$ & $n=5$ & $n=6$ \\
\hline Constant $(\chi)$ & $-2.77 * * *$ & $-2.74 * * *$ & $-2.54 * * *$ & $-2.00 * * *$ & $-1.80 * * *$ & $-1.50 * * *$ \\
\hline Constant $(\gamma)$ & -0.01 & 0.19 & 0.08 & -0.16 & -0.40 & $-0.82 * *$ \\
\hline Future rate $(\alpha)$ & 0.07 & $0.24 * *$ & $0.27 * *$ & $0.22 *$ & $0.35 *$ & $0.47 * * *$ \\
\hline Payrolls ( $\beta$ ) & -14.57 & $-54.63 * * *$ & $-56.30 * * *$ & -33.13 & $-59.48 *$ & $-63.95 * *$ \\
\hline Bias (ס1999) & -0.30 & 0.22 & 0.21 & 0.05 & 0.13 & 0.20 \\
\hline Guidance ( 82003 ) & $-0.84 * * *$ & $-0.71 * *$ & -0.41 & -0.05 & 0.02 & -0.04 \\
\hline Speeches (ৎ) & $-0.06 * *$ & $-0.04 *$ & -0.02 & -0.03 & -0.04 & -0.04 \\
\hline
\end{tabular}

The results presented in Table 3 suggest that more speeches and testimony help the markets to better understand monetary policy and significantly improve predictability at the one month horizon and, with weak significance, at two months ahead ${ }^{7}$. With an average of almost eight speeches per month, the

\footnotetext{
${ }^{7}$ Those familiar with the practice of the "black-out period", whereby FOMC members refrain from commenting on monetary policy around rate setting meetings and the Chairman's semiannual testimony to the Congress, may suspect that this explains the results. Fewer speeches due to the black-out might be correlated with any impact that the outcome of monetary policy meetings or testimony have (both in terms of reaction to surprise rate moves or new information contained in the statement or testimony). However, due to the six week schedule of the FOMC and the two months of the Chairman's the semi-annual testimony, $80 \%$ of the months include a black-out period. In any case, the inclusion of a dummy for months with a meeting or semiannual testimony does not affect the outcome.
} 
cumulative effects are typically a little more than half as strong the effect of explicit policy guidance and approximately on par with the effect of the early communication reforms. $^{8}$

\section{Alternative specifications}

In Section $3 \mathrm{I}$ argue, on the basis of economic and statistical considerations, for the FOMC minutes (1993), the release of the bias (1999) and guidance on the direction of interest rates (2003) as the most logical starting points for the three dummies in my analysis. The last of these was a clear-cut change in communication policy that was communicated as such by the FOMC and, when feasible, implemented in a similar fashion up to the present. The FOMC minutes and the bias, on the other hand, were closely followed by other different reforms. Indeed, as discussed above, both do not appear to be especially substantive reforms in their own right. I argue that the dummies represent a series of reforms and the impact on predictability should thus be seen as coming from their collective effect. However, there is a risk that starting the dummy too soon on an irrelevant, or worse, counterproductive reform could hide the impact of the other reforms.

To check if some of the other reforms might be better starting points for the first two dummies I compare how well different specifications fit the data. Table 4 presents the $\mathrm{R}^{2}$ of models with alternate initial reforms. ${ }^{9}$ The $\mathrm{R}^{2}$ is reported for each of the six variations of the minutes, statement, rationale, bias and outlook variables (see Table 1 for descriptions) for each of the $1-6$ month ahead timeframes. The last column is the average of the $\mathrm{R}^{2}$ over all timeframes for that specification. The asterisk denotes the highest $\mathrm{R}^{2}$ within the column. ${ }^{10}$ Complete regression results from these specifications are shown in the Appendix (with the exception for the minutes-balance-guidance variant, which is presented below in Table 5).

\footnotetext{
${ }^{8}$ While the evidence here suggests that on average more speeches improve predictability, there is also evidence from Ehrmann and Fratzscher (2007a) that if the views expressed by policy makers become more dispersed that this may hamper predictability.

${ }^{9} \mathrm{I}$ chose $\mathrm{R}^{2}$ rather than other goodness-of-fit measures such as adjusted $\mathrm{R}^{2}$, Aikaike, Schwarz and Hannan-Quinn. The essential difference between these measures is how they discount for the number of dependent variables in the model. Here we have the same number of variables in all cases, so all measures deliver the same ordering of the model.

${ }^{10}$ The highest value is based on the unrounded figures. Due to the use of only 3 decimal places, it may appear as if some values are equal in the table.
} 


\begin{tabular}{lccccccc}
\hline R-squared & $\mathbf{1}$ & $\mathbf{2}$ & $\mathbf{3}$ & $\mathbf{4}$ & $\mathbf{5}$ & $\mathbf{6}$ & average \\
\hline minutes, bias, guidance & 0.217 & 0.274 & 0.233 & $0.136 *$ & 0.139 & 0.189 & 0.198 \\
statement, bias, guidance & 0.213 & 0.264 & 0.228 & 0.126 & $0.139 *$ & 0.189 & 0.193 \\
rationale, bias, guidance & 0.217 & 0.270 & 0.233 & 0.129 & 0.138 & $0.189 *$ & 0.196 \\
minutes, balance, guidance & $0.223 *$ & $0.275 *$ & 0.234 & 0.136 & 0.139 & 0.187 & $0.199 *$ \\
statement, balance, guidance & 0.219 & 0.265 & 0.228 & 0.125 & 0.139 & 0.186 & 0.194 \\
rationale, balance, guidance & 0.222 & 0.270 & $0.234 *$ & 0.129 & 0.138 & 0.188 & 0.197 \\
& & & & & & & *highest $\mathbf{R}^{2}$
\end{tabular}

Table 4: Model comparisons using $\mathbf{R}^{2}$

Differences between the specifications are very small, all within a range of 0.005. The performance of the models is thus not very sensitive to the exact starting point of the dummies ${ }^{11}$. Overall the specification used in the text above, minutes-bias-guidance (first row) is beaten by 0.001 by the minutes-balanceguidance variant (fourth row). In other words, starting the first dummy at the 1993 minutes is supported by comparing the $\mathrm{R}^{2}$ measures ${ }^{12}$ while there may be some doubt about the choice for the bias-dummy over the balance-dummy. A closer look at the results from the minutes-bias-guidance specification is thus warranted and shown in Table 5 .

\begin{tabular}{lcccccc}
\hline & $\mathbf{n}=\mathbf{1}$ & $\mathbf{n = 2}$ & $\mathbf{n = 3}$ & $\mathbf{n = 4}$ & $\mathbf{n = 5}$ & $\mathbf{n}=\mathbf{6}$ \\
\hline Constant $(\boldsymbol{\chi})$ & $-2.67 * * *$ & $-2.09 * * *$ & $-1.88 * * *$ & $-1.49 * * *$ & $-1.29 * * *$ & $-1.81 * * *$ \\
Constant $(\boldsymbol{\gamma})$ & 0.00 & $0.36 *$ & 0.31 & -0.06 & -0.15 & $-0.52 * *$ \\
Future rate $(\boldsymbol{\alpha})$ & $0.08 *$ & $0.08 *$ & $0.11 *$ & $0.13 * *$ & $0.18 * *$ & $0.35 * * *$ \\
Payrolls $(\boldsymbol{\beta})$ & $-17.60 * *$ & $-29.01 * * *$ & $-30.71 * * *$ & $-21.94 * *$ & $-30.51 * *$ & $-51.12 * * *$ \\
Minutes $(\boldsymbol{\delta 1 9 9 3 )}$ & $-0.51 *$ & $-0.65 * * *$ & $-0.53 *$ & $-0.58 * *$ & $-0.54 *$ & 0.17 \\
Balance & -0.42 & -0.12 & 0.04 & 0.07 & 0.04 & 0.02 \\
Guidance $(\mathbf{\delta 2 0 0 3})$ & $-0.84 * * *$ & $-0.73 * *$ & -0.56 & -0.26 & -0.14 & -0.04 \\
\hline
\end{tabular}

$* \mathrm{p}<10 \% * * \mathrm{p}<5 \% * * * \mathrm{p}<1 \%$

Table 5: Impact of reforms on Fed funds future error, balance of risks versus bias

\footnotetext{
${ }^{11}$ Endogenous break anlaysis is potentially another approach to identifying changes in the predictability of the Fed funds rate that could be caused by shifts in communication policy. However, considering there are specific dates for the start of each policy the fundamental problem of this analysis is not identifying where potential breaks might be. Indeed, the question is somewhat the reverse. We can identify changes in policy, the question is if these had a significant effect. Furthermore, with model specifications of various candidates for the first and second dummy having such similar explanatory power, it does not seem likely that a particular breakpoint would be useful in selecting one dummy starting point from the other.

${ }^{12}$ Another argument in favor of the minutes-dummy is that in the table in the Appendix it is significant for a longer forecast horizons than either the statement-dummy or the rationaledummy.
} 
In terms of significance of coefficients, the results in Table 5 are very similar to Table 3. The only qualitative difference is that the guidance dummy is not significant at the three month timeframe in Table 5. Starting the second dummy at the introduction of the balance-of-risks, rather than the release of the bias, results in a slightly stronger decline in errors. This makes sense, given the perception by FOMC members that the release of the bias was not a success. However, in both variants the coefficient for the second dummy remains insignificant. As the very similar $\mathrm{R}^{2}$ measures suggest, the results are basically comparable. Given this, I continue to favor the release of the bias as a more natural starting point for the second dummy, because it is clearly a predecessor to the balance-of-payments and signaled the start of a more forward looking communication policy distinct from the reforms of the early to mid 1990s (which focused instead on explaining current monetary policy).

\section{Conclusion}

Distinguishing different periods of innovation in the communication policy of the Federal Open Market Committee reveals important differences between these reforms. From 2003 the accuracy of the Fed funds futures was aided by the FOMC's explicit guidance about the likely direction of interest rates. Signaling the short term "bias" of monetary policy or the "balance of risks", however, did not help. The earlier reforms of the mid 1990s, when the FOMC introduced the new minutes and the post-meeting statement, also improved predictability. Explaining why monetary policy was set as it was probably helped the markets to better understand and anticipate interest rate changes even though the FOMC did not communicate its own outlook until later. It is also possible that during the same period FOMC members became more communicative through already available channels of communication. Evidence that speeches and Congressional testimony improves predictability suggests that such "old" channels may also have played a role in advancing predictability. 


\section{Appendix}

\begin{tabular}{lcccccc}
\hline & $\mathbf{n}=\mathbf{1}$ & $\mathbf{n = 2}$ & $\mathbf{n}=\mathbf{3}$ & $\mathbf{n = 4}$ & $\mathbf{n}=\mathbf{5}$ & $\mathbf{n = 6}$ \\
\hline Constant $(\chi)$ & $-2.75 * * *$ & $-2.22 * * *$ & $-1.99 * * *$ & $-1.68 * * *$ & $-1.36 * * *$ & $-1.68 * * *$ \\
Constant $(\gamma)$ & 0.01 & 0.33 & 0.30 & -0.05 & -0.15 & $-0.54 * *$ \\
Future rate $(\boldsymbol{\alpha})$ & $0.08 *$ & $0.09 *$ & $0.12 * *$ & $0.15 * *$ & $0.18 * * *$ & $0.34 * * *$ \\
Payrolls $(\boldsymbol{\beta})$ & $-16.91 * *$ & $-31.08 * * *$ & $-33.42 * * *$ & $-28.16 * * *$ & $-32.15 * * *$ & $-45.92 * * *$ \\
Statement & $-0.47 *$ & $-0.54 * *$ & -0.40 & -0.30 & $-0.51 * *$ & -0.05 \\
Bias $(\boldsymbol{\delta 1 9 9 9 )}$ & -0.27 & -0.03 & -0.01 & -0.14 & 0.08 & 0.22 \\
Guidance $(\mathbf{\delta 2 0 0 3})$ & $-0.95 * * *$ & $-0.79 * *$ & $-0.53 *$ & -0.15 & -0.13 & -0.15 \\
\hline
\end{tabular}

*p $<10 \% * * \mathrm{p}<5 \% * * * \mathrm{p}<1 \%$

Table 6: Impact of reforms on Fed funds future error, statement rather than minutes

\begin{tabular}{lcccccc}
\hline & $\mathbf{n}=\mathbf{1}$ & $\mathbf{n}=\mathbf{2}$ & $\mathbf{n}=\mathbf{3}$ & $\mathbf{n}=\mathbf{4}$ & $\mathbf{n}=\mathbf{5}$ & $\mathbf{n = 6}$ \\
\hline Constant $(\chi)$ & $-2.75 * * *$ & $-2.21 * * *$ & $-1.97 * * *$ & $-1.66 * * *$ & $-1.41 * * *$ & $-1.77 * * *$ \\
Constant $(\gamma)$ & 0.00 & $0.35 *$ & 0.30 & -0.05 & -0.15 & $-0.55 * *$ \\
Future rate $(\boldsymbol{\alpha})$ & $0.08 *$ & $0.09 *$ & $0.12 * *$ & $0.15 * *$ & $0.19 * * *$ & $0.35 * * *$ \\
Payrolls $(\boldsymbol{\beta})$ & $-16.98^{* *}$ & $-29.68 * * *$ & $-33.04 * * *$ & $-27.44 * * *$ & $-33.08 * * *$ & $-48.90 * * *$ \\
Rationale & $-0.53 * *$ & $-0.63 * * *$ & $-0.49 *$ & -0.36 & $-0.48 * *$ & 0.08 \\
Bias $(\boldsymbol{\delta 1 9 9 9 )}$ & -0.21 & 0.04 & 0.06 & -0.09 & 0.09 & 0.16 \\
Guidance $(\boldsymbol{\delta 2 0 0 3})$ & $-0.94 * * *$ & $-0.79 * *$ & $-0.53 *$ & -0.15 & -0.12 & -0.14 \\
\hline
\end{tabular}

*p $<10 \% * * \mathrm{p}<5 \% * * * \mathrm{p}<1 \%$

Table 7: Impact of reforms on Fed funds future error, rationale rather than minutes

\begin{tabular}{lcccccc}
\hline & $\mathbf{n = 1}$ & $\mathbf{n = 2}$ & $\mathbf{n}=\mathbf{3}$ & $\mathbf{n = 4}$ & $\mathbf{n = 5}$ & $\mathbf{n = 6}$ \\
\hline Constant $(\chi)$ & $-2.76 * * *$ & $-2.22 * * *$ & $-1.99 * * *$ & $-1.67 * * *$ & $-1.36 * * *$ & $-1.70 * * *$ \\
Constant $(\gamma)$ & -0.01 & 0.33 & 0.30 & -0.07 & -0.15 & $-0.51 *$ \\
Future rate $(\boldsymbol{\alpha})$ & $0.08 *$ & $0.10 *$ & $0.12 * *$ & $0.15 * *$ & $0.18 * * *$ & $0.33 * * *$ \\
Payrolls $(\boldsymbol{\beta})$ & $-17.52 * *$ & $-31.22 * * *$ & $-33.20 * * *$ & $-26.86 * *$ & $-32.24 * * *$ & $-47.65 * * *$ \\
Statement & -0.43 & $-0.50 * *$ & -0.42 & -0.37 & $-0.50 *$ & 0.04 \\
Balance & -0.42 & -0.13 & 0.04 & 0.01 & 0.07 & 0.06 \\
Guidance $(\mathbf{\delta 2 0 0 3})$ & $-0.84 * * *$ & $-0.73 * *$ & -0.56 & -0.24 & -0.13 & -0.06 \\
\hline
\end{tabular}

$* \mathrm{p}<10 \% * * \mathrm{p}<5 \% * * * \mathrm{p}<1 \%$

Table 8: Impact of reforms on Fed funds future error, statement rather than minutes, balance of risks rather than bias 


\begin{tabular}{lcccccc}
\hline & $\mathbf{n = 1}$ & $\mathbf{n}=\mathbf{2}$ & $\mathbf{n}=\mathbf{3}$ & $\mathbf{n}=\mathbf{4}$ & $\mathbf{n}=\mathbf{5}$ & $\mathbf{n = 6}$ \\
\hline Constant $(\boldsymbol{\chi})$ & $-2.75 * * *$ & $-2.21 * * *$ & $-1.97 * * *$ & $-1.65 * * *$ & $-1.41 * * *$ & $-1.78 * * *$ \\
Constant $(\boldsymbol{\gamma})$ & -0.02 & 0.34 & 0.30 & -0.07 & -0.15 & $-0.52 * *$ \\
Future rate $(\boldsymbol{\alpha})$ & $0.08 * *$ & $0.09 *$ & $0.12 * *$ & $0.15 * *$ & $0.19 * * *$ & $0.35 * * *$ \\
Payrolls $(\boldsymbol{\beta})$ & $-17.55 * *$ & $-30.03 * * *$ & $-32.93 * * *$ & $-26.18 * * *$ & $-33.24 * * *$ & $-50.61 * * *$ \\
Rationale & $-0.49 *$ & $-0.58 * * *$ & $-0.50 *$ & -0.44 & $-0.47 *$ & 0.17 \\
Balance & -0.37 & -0.07 & 0.10 & 0.06 & 0.07 & 0.00 \\
Guidance $(\boldsymbol{\delta 2 0 0 3})$ & $-0.84 * * *$ & $-0.73 * *$ & -0.56 & -0.24 & -0.12 & -0.05 \\
\hline$* \mathrm{p}<10 \% * * \mathrm{p}<5 \% * * * \mathrm{p}<1 \%$ & & & & &
\end{tabular}

Table 9: Impact of reforms on Fed funds future error, rationale rather than minutes and balance of risks rather than bias 


\section{References}

Axilrod, S. H.: 2009, Inside the Fed, MIT Press.

Bernanke, B.: 2004, Central bank talk and monetary policy. Speech, 7 October.

Campbell, J. Y. and Shiller, R. J.: 1991, Yield spreads and interest rate movements: A bird's eye view, The Review of Economic Studies 58(3), 495-514.

Carlson, J., Craig, B., Higgins, P. and Melick, W.: 2006, FOMC communications and the predictability of near-term policy decisions. Federal Reserve of Cleveland Review.

Cochrane, J. H. and Piazzesi, M.: 2005, Bond risk premia, American Economic Review 95(1), 138-160.

Coppel, J. and Connolly, E.: 2003, What do financial market data tell us about monetary policy transparency? Reserve Bank of Australia Working Paper.

Dale, S., Orphanides, A. and Osterholm, P.: 2008, Imperfect central bank communication - information vs. distraction. IMF Working Paper 08/60.

Demertzis, M. and Hoeberichts, M.: 2007, The costs of increasing transparency, Open Economies Review 18, 263-280.

Ehrmann, M. and Fratzscher, M.: 2007a, Social value of public information: Testing the limits of transparency. ECB Working Paper No. 821.

Ehrmann, M. and Fratzscher, M.: 2007b, Transparency, disclosure and the federal reserve, Journal of Central Banking .

Fama, E. F. and Bliss, R. R.: 1987, The information in long-maturity forward rates, The American Economic Review 77(4), 680-692.

Gurkaynak, R., Sack, B. P. and Swanson, E. T.: 2007, Market-based measures of monetary policy expectations, Journal of Business and Economic Statistics $\mathbf{2 5}(2)$.

Hayo, B. and Neuenkirch, M.: 2009, Does FOMC communication help predicting federal funds target rate changes? MAGKS Joint Discussion Paper Series in Economics, No. 25-2009.

Holmsen, A., Qvigstad, J. F., Øistein Røisland and Solberg-Johansen, K.: 2008, Communicating monetary policy intentions: The case of Norges Bank. Norges Bank Working Paper 2008-20.

Jansen, D.-J. and de Haan, J.: 2009, Has ECB communication been helpful in predicting interest rate decisions? an evaluation of the early years of the economic and monetary union, Applied Economics 41(16), 1995-2003. 
King, M.: 2000, Address to the joint luncheon of the american ecnomic association and the american finance association. Speech, 7 January.

Kool, C., Middeldorp, M. and Rosenkranz, S.: 2011, Central bank transparency and the crowding out of information in the financial markets, Journal of Money, Credit and Banking. Forthcoming.

Kwan, S.: 2007, On forecasting future monetary policy: Has forward-looking language mattered? Federal Reserve Bank of San Francisco Economic Letter 2007-15.

Lange, J., Sack, B. and Whitesell, W.: 2003, Anticipations of monetary policy in financial markets, Journal of Money, Credit and Banking 35(6), 889-909.

Lildholdt, P. and Wetherilt, A. V.: 2004, Anticipation of monetary policy in UK financial markets. Bank of England Working Paper 241.

Middeldorp, M. and Rosenkranz, S.: 2011, Central bank communication and the crowding out of private information in an experimental asset market. Federal Reserve Bank of New York Staff Report.

Mizen, P.: 2009, What can we learn from central bankers' words? some nonparametric tests for the ECB, Economic Letters 103, 29-32.

Morris, S. and Shin, H. S.: 2002, Social value of public information, The American Economic Review 92(5), 1521-1534.

Murdzhev, A. and Tomljanovich, M.: 2006, What is the color of Alan Greenspan's tie? how central bank policy announcements have changed financial markets, Eastern Economic Journal 32(4).

Pianalto, S.: 2005, Expectations, communications and monetary policy, Federal Reserve Bank of Cleveland Economic Commentary .

Piazzesi, M. and Swanson, E.: 2008, Futures prices as risk-adjusted forecasts of monetary policy, Journal of Monetary Economics 55, 677-691.

Poole, W.: 2003, Fed transparency: How, not whether. November 1 Luncheon Address before the Global Interdependence Center, Federal Reserve Bank of Philadelphia.

Rafferty, M. and Tomljanovich, M.: 2002, Central bank transparency and market efficiency: An econometric analysis, Journal of Economics and Finance 26(2), 150-161.

Rasche, R. H. and Thornton, D. L.: 2002, The FOMC's balance-of-risks statement and market expectations of policy actions, The Federal Reserve Bank of St. Louis Review.

Sack, B.: 2004, Extracting the expected path of monetary policy from futures rates, The Journal of Futures Markets 24(8), 733-754. 
Stambaugh, R. F.: 1988, The information in forward rates, Journal of Financial Economics 21, 41-70.

Sturm, J.-E. and de Haan, J.: 2009, Does central bank communication really lead to better forecasts of policy decisions? new evidenced based on a Taylor rule model for the ECB. KOF Working Paper 2009 No. 236.

Svensson, L. E.: 2006, Social value of public information: Morris and shin (2002) is actually pro transparency, not con, The American Economic Review 96(1), 448-452.

Swanson, E.: 2006, Have increases in Federal Reserve transparency improved private sector interest rate forecasts, Journal of Money, Credit and Banking 38, $792-819$.

Tomljanovich, M.: 2004, Does central bank transparency impact financial markets? a cross country econometric analysis, Southern Economic Journal 